\title{
Geogebra as a Scaffolding Tool for Exploring Analytic Geometry Structure and Developing Mathematical Thinking of Diverse Achievers
}

\author{
Muhammad Khalil ${ }^{1 *}$, Umair Khalil ${ }^{2}$, Zahoor ul Haq ${ }^{3}$ \\ ${ }^{1}$ Lecturer, FG Boys Inter College Mardan Cantt., PAKISTAN \\ ${ }^{2}$ Assistant Professor, AWKUM Mardan, PAKISTAN \\ ${ }^{3}$ Lecturer, Department of Education, Bacha Khan University Charsadda KPK, PAKISTAN \\ *CORRESPONDENCE: $\square$ khalilmathematics1977@gmail.com
}

\begin{abstract}
One of the reasons to use technology in education is to visualize and explore the insight of mathematics with optimum possibilities. Geogebra gives visual meaning to symbolic ideas along with optimum dynamic possibilities. The purpose of this experimental study was to know about the potential effect of dynamic geometry software on diverse students' mathematical thinking behavior. For which a sample of forty students (grade-12) of F.G Inter College for Boys Mardan Cantt was selected. On the of their previous grade-11 standardized exams two groups along with their nested factors higher and lower achievers students were constructed. To investigate students' mathematical thinking basis in the subject of analytic geometry, a model behavior of thinking with its six aspects was constructed on the basis of this model a well-design criterion test was developed for data collection. The six dependent variables were combined together to form the total mathematical thinking in this research study. Further, six week experiments of 22 lessons were prepared and two teaching methods traditional vs DGS (Dynamic Geometry Software) aided instructions were tested for two groups with almost equal statistical background and with the same compatibility in the biological age. Two hypotheses were carried out i.e. Treatment does not significantly affect the higher and low achievers of the two groups in mathematical thinking mean scores. To check the significant effect of the treatment on the students' overall mathematical thinking variable across the groups, the two-way (ANOVA) was used and analyzed through as statistical tool SPSS. The study findings showed that treatment did significantly affect the higher and lower achievers of the two groups in mathematical thinking mean scores.
\end{abstract}

Keywords: mathematical thinking, Geogebra, diverse achiever

\section{INTRODUCTION}

\section{Analytic Geometry}

Evidences show that the $17^{\text {th }}$ century was the century of mathematical advancements. This century gave birth to a great French philosopher, mathematician, scientist and psychologist "Rene Descartes", is called the father of philosophy and analytic geometry. He combined two distinct disciplines; algebra and geometry into one, and was the first to use algebraic process to solve geometry problem (Evans, 2014; Hergenhahn \& Henley, 2013; KPK text Book and Punjab text Book for $2^{\text {nd }}$ year). So, analytic geometry or coordinate geometry is a discipline that combines the techniques of algebra with those of geometry. To put it in another way, analytic

Article History: Received 24 November $2018 \bullet$ Revised 22 December $2018 \bullet$ Accepted 22 December 2018

(C) 2019 by the authors; licensee Modestum Ltd., UK. Open Access terms of the Creative Commons Attribution 4.0 International License (http://creativecommons.org/licenses/by/4.0/) apply. The license permits unrestricted use, distribution, and reproduction in any medium, on the condition that users give exact credit to the original author(s) and the source, provide a link to the Creative Commons license, and indicate if they made any changes. 
geometry enables us to apply algebraic methods and equations to solution of problems in geometry and conversely to obtain geometric representations of algebraic equations. In Pakistan, informal analytic geometry is taught at high school and formally it is a core subject at higher secondary level but due to the dual nature of this subject students visualize most of the concepts mentally with great labor.

In analytic geometry, every object of analytic geometry is a structure which results in different form: expressions, equations, relations and functions. Geometrically every structure constitutes of points and the algebraic form of this constitutes of variables, parameters and constants. Like Lew (2004), this idea through model behavior can be represented as:

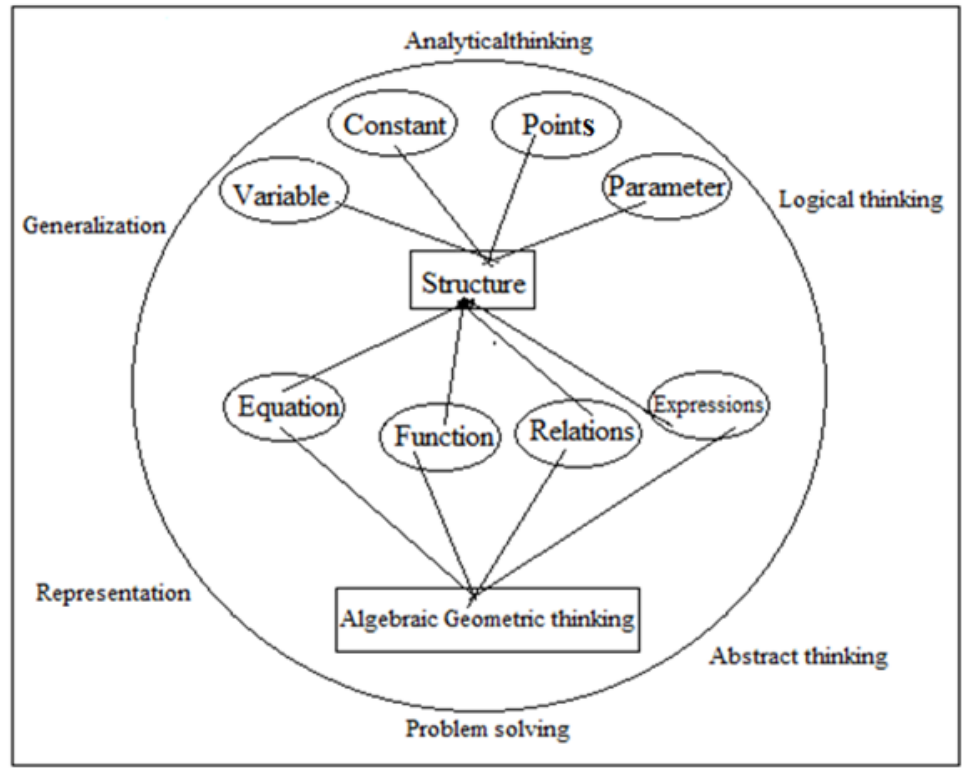

Figure 1. Web of analytic geometry structure

As algebraic concepts are everywhere in school geometry, and it is a best approach to the solution of problem in geometry by involving and understanding the concepts of variables (Dindyal, 2007). So, to learn and understand Analytic Geometry both Algebraic and Geometric analysis of each nested results of structure, is important and the six aspects of algebraic geometric thinking model (Generalization, Analysis, Logical thinking, Abstract thinking, Problem solving, Representation) is an approach towards the understanding of analytic geometry and to conceptualize the concept in analytic geometry, the six mathematical thinking skills of dual nature are essential and in this study, it has given the name of algebraic geometric thinking model. The model is a hybrid of Algebra and Geometry. Further to understand Analytic geometry both the aspects (algebraic and geometric thinking) are necessary.

As, for every algebraic structure, there is equal geometrical representation in coordinate geometry. So, the application of a similar approach to Descartes helped in combining algebra and geometry into a software language (GeoGebra) by Markus Hohenwarter. GeoGebra is being used at every level in Mathematics education.

\section{Importance of Mathematical Thinking}

In this technological globe it is not easy to survive without the necessary skill of mathematics and mathematical thinking. The need of mathematical thinking for a person to live in this society and the advancement of technology are highly correlated. Those who are well-equipped with critical thinking skill, they can find the ways in the solution of complex problems in different disciplines, which is only possible with the sophisticated knowledge of mathematics (National Curriculums for mathematics, 2006).

\section{Technology Standard}

Learning needs tools to accomplish its objectives. For this reason, different tools are being used to make learning process meaningful. Technology is one of the essential tools in teaching learning process. And it is 
the technology which concretizes the abstract concept through effective modeling and representation. To integrate technology in teaching learning mathematics is a complex issue, and to communicate and inculcate the mathematical concept, teachers must equip themselves with technological and didactic skill (Ang, 2010; Gomez-Chacon \& Joglar, 2010). Moreover, technology is one of the six principles for school mathematics (NCTM, 2000), under this Principle, technology affects the three basic areas:

i. Technology enhances mathematics learning through multiple representations of an object and to view it with different perspectives.

ii. Technology support and give velocity to mathematics teaching, if teacher use technology in an appropriate way, by creating task and through visualization of the task.

iii. Technology influences what mathematics has taught.

\section{Teacher's Role in the Technology Integrated Environment}

Despite, the potential power of technology in teaching learning process, it cannot replace a good teacher. But technology only transforms its role in the classroom. Likewise, mind without effective and appropriate use, results in no meaning, similarly technology in classroom always depends on its functional role rather than its constructional role. As, stated in "NCTM document" (2000), the effectiveness of technology in the classroom is always dependent on teacher, that how he/she uses it.

In non-integrated technology environment the role of a teacher is always active and teacher-centered and students are less involved in learning process. On the contrary, in integrated learning environment, the role of a teacher is to become a coach, a guide and get close to the students. Students need to be completely involved in learning and in learning process, which is the main objective of mathematics education. Teacher facilitates students to construct their own knowledge and monopoly of teacher in learning process replace as partner (Shimamoto, 2012). Along with this teacher do assessment during the learning process of student understanding.

\section{Mathematics Education Reformation}

To improve the mathematics education through reform in mathematics education is common across the world. For this, different possible initiatives have been done and are still going on in the form of curriculum reform and resource development. Pre-service and in-service teacher education programmes are encouraged in these initiatives to improve the quality of instructions and establish the class-room environment interactive and meaningful. As, the existing mathematics curriculum demands for conceptual teaching and the development of mathematical thinking, so, teachers need to change their current status of teaching practice. The teacher must know how to equip himself/herself with such technological tools that promote (1) cooperative and collaborative learning environment (2) supporting students' creativity in developing rational understanding of concepts of mathematics. The improvement in the quality of mathematics teaching and learning must begin with an understanding of the conceptions held by teacher. The teacher views mathematics teaching and learning as the prerequisite for the development of mathematics classroom. The teachers' knowledge, beliefs and concepts play a vital role in their thinking and behaviors which are influential for their teaching practices. While implementing reforms, teachers' views must be taken on board (Amirali \& Halai, 2010; National Curriculum for Mathematics, 2006).

\section{New Aspects that Emerge with Geogebra Environment in Teaching Analytic-Geometry}

As, Geogebra is a technological tool that gives a different way of learning environment for concept learning that is, it provides dynamic geometry features with symbolic approach. So, it is effective to teach analytic geometry with Geogebra aided instructions (Kushwaha, et al, 2013; Ljajko, \& Ibro, 2013). In higher mathematics classes, the understanding of abstract concepts is essential, and is one of the main objectives of mathematics education. And students always struggle with these abstract concepts, but through the use of manipulative most of these concepts can be concretized. Moreover, because of Geogebra, new aspects are emerged in teaching of analytic geometry and due to these new technological aspects, so it assists to integrate Geogebra in analytic geometry. Some of the Geogebra aspects are:

i. Virtual manipulation: Geogebra gives virtual manipulation of an abstract object in a concrete way through multiple representations (Özgün-Koca \& Meagher, 2012).

ii. The conjunction of algebraic and geometric thinking: Geogebra is straightforward software that gives the simultaneous representation of algebraic and geometric object along with the process (Little, 2009). 
iii. The process of concept can be seen through discrete and continuous way by using slider and animation.

iv. Idea processing: Geogebra has the ability to act on object through different possibility and then process the possible ideas in more rapid, accurate and gaining the spontaneous feedback in an exact way.

v. Analytic and synthetic views: Geogebra has the potential through which students can observe and translate the ideas of different concept in analytic geometry, in both analytic and synthetic ways across different transformation.

\section{The Two Main Objectives of the Study Were}

i. To find out the potential effect of Geogebra aided instructions in analytic geometry subject.

ii. To explore the Geogebra effect on diverse achievers (high and low achievers) of the two groups at significance level.

\section{Hypotheses of the Study Were}

Ho1: GeoGebra aided instructions do not affect significantly the experimental high achievers in comparison to control high achievers in mathematical thinking posttest.

Ho2: GeoGebra aided instructions do not affect significantly the experimental low achievers in comparison to control high achievers in mathematical thinking posttest.

\section{METHODOLOGY}

A sample of forty students $(n=40)$ of grade-12 of F.G Inter College For Boys Mardan Cantt for this matched subjects design (experimental study) were selected out of total population of all the government and nongovernment higher secondary, 384207 male students (EMIS 2013-2014). They were ranked according to their previous grade-11 exam results in mathematics subject. And through pair random sampling, they were assigned to experimental and control group (Gay \& Mills, 2009). To explore the geogebra treatment effects on higher and lower achievers students of both the groups, the students of both the groups on the bases of their achievement were divided into two halves: the higher achievers (Marks>60) and the lower achievers (Marks<60). The first twelve students of each group were constructed as higher achievers and last eight students of each group were constructed as lower achievers (Ary et al., 2013, Cohen et al. 2011; Farooq, 2001; Goodwin, 2010; Nestor \& Schutt, 2014; Newby, 2014).

Table 1. Research Design

\begin{tabular}{ccccc}
\hline Standardized test & Pair random \\
scores Ranking & Sampling & Experimental & X(Treatment) & Posttests \\
\cline { 3 - 5 } & & Control Group & -...-.-.-. & Posttests \\
\hline
\end{tabular}

Six week experiments of 22 lessons were prepared and uploaded on Geogebra tube (http://tube.geogebra.org/mkhalilkhan).The experiment was conducted on $1^{\text {st }}$ August 2014 and ended on 19th September 2014. In which, the experimental group was given a total of six/ 6 week Geogebra-aided treatment in a well-equipped computer lab under the supervision of researcher. The computers were arranged in U-shape and students worked there in pairs. On contrary to that, the control group was taught by the same teacher without Geogebra-aided instructions.

\section{OUTCOMES OF THE STUDY}

Table 2 reports the descriptive statistics for both higher and lower achiever groups of (experimental group \& control group). It shows that the average score obtained by the Exp.H.A group was higher than that of the Cont.H.A group. Also the average marks obtained by Exp.H.A group were higher than that of the Cont.L.A group in overall mathematical thinking. At the same time if we look at the column of the standard deviation, we can see that the standard deviation of the experimental group (Exp.H.A \& Exp.L.A) is lower than that of the control group (Cont.H.A \& Cont.L.A). The descriptive statistics clearly indicate that the experimental group (H.A and L.A) performed better than that of the control group (H.A and L.A). 
Table 2. High achiever and low achiever groups performance on mathematical thinking post-test

\begin{tabular}{cccc}
\hline Group & $\mathbf{N}$ & Mean & Std. Deviation \\
\hline Exp. H.A & 12 & 123.33 & 11.01 \\
\hline Exp.L.A & 8 & 104.50 & 12.04 \\
\hline Cont. H.A & 12 & 108.83 & 12.52 \\
\hline Cont. L.A & 8 & 68.50 & 12.22 \\
\hline
\end{tabular}

Table 3 shows the ANOVA test value. In this case, the test value $=34.82$, and the $p$-value in the significance column is less than 0.05. So, it is decided that there was a significant difference across the groups after treatment. As ANOVA only tells us generally, about the experimental variable effect and, it does not show specifically about the particular effected groups. So, to investigate that, which of the groups' means was significant, for this, we apply post-hoc test (Gravetter \& Wallnau, 2012).

Table 3. Tests of between-subjects effects for mathematical thinking posttest

\begin{tabular}{ccccccccc}
\hline Source & $\begin{array}{c}\text { Type III } \\
\text { Sum of } \\
\text { Squares }\end{array}$ & df & Mean Square & F & Sig. $\begin{array}{c}\text { Partial } \\
\text { Eta } \\
\text { Squared }\end{array}$ & $\begin{array}{c}\text { Noncent. } \\
\text { Parameter }\end{array}$ & $\begin{array}{c}\text { Observed } \\
\text { Powerb }\end{array}$ \\
\hline $\begin{array}{c}\text { Corrected } \\
\text { Model }\end{array}$ & $14847.17^{\mathrm{a}}$ & 3 & 4949.06 & 34.82 & .000 & .744 & 104.47 & 1 \\
\hline Intercept & 393984.07 & 1 & 393984.07 & 2772.2 & .000 & .987 & 2772.19 & 1 \\
\hline Group & 14847.17 & 3 & 4949.06 & 34.82 & .000 & .744 & 104.47 & 1 \\
\hline Error & 5116.33 & 36 & 142.12 & & & & & \\
\hline Total & 454686.00 & 40 & & & & & & \\
\hline $\begin{array}{c}\text { Corrected } \\
\text { Total }\end{array}$ & 19963.50 & 39 & & & & & & \\
\hline
\end{tabular}

The $\mathrm{F}$ tests the effect of group4. This test is based on the linearly independent pairwise comparisons among the estimated marginal means.

a. $\mathrm{R}$ Squared $=.744$ (Adjusted R Squared $=0.722$ )

b. Computed using alpha $=0.05$

Table 4 shows that the treatment effected the mean scores of the both the groups (Exp.H.A and Cont.H.A) at a significant level. If we look at the column of significance values for Exp.H.A and Cont.H.A, the p-value is 0.031 which is less than 0.05. In similar way, for Exp.H.A and Cont.L.A, the p-value is also less than 0.05. That is, both the tests values are insignificant. So, the summary of the two null hypotheses is:

Table 4. Multiple comparisons between-subjects factors on the mathematical thinking post-test

\begin{tabular}{ccccc}
\hline (I) Group & (J) Group & Mean Difference (I-J) & Std. Error & Sig. \\
\hline \multirow{3}{*}{ Exp.H.A } & Exp.L.A & $18.83^{*}$ & 5.44 & .008 \\
\cline { 2 - 5 } & Cont.H.A & $14.50^{*}$ & 4.87 & .031 \\
\cline { 2 - 5 } & Cont.L.A & $54.83^{*}$ & 5.44 & .000 \\
\hline \multirow{3}{*}{ Exp.L.A } & Exp.H.A & $-18.83^{*}$ & 5.44 & .008 \\
& Cont.H.A & -4.33 & 5.44 & 1.000 \\
\cline { 2 - 5 } & Cont.L.A & $36.00^{*}$ & 5.96 & .000 \\
\hline
\end{tabular}

We reject Ho1: Treatment did significantly affect the higher achievers of the two groups in mathematical thinking mean scores.

We also reject $\mathrm{H}_{02}$ and accept the alternative that is; treatment did significantly affect the lower achievers of the two groups in mathematical thinking mean's scores. Below is the graph that shows the performances of experimental high and lower achievers as compared with the control high and lower achievers. Below is the graph that shows the performances of experimental high and lower achievers in compare with the control high and lower achievers. 


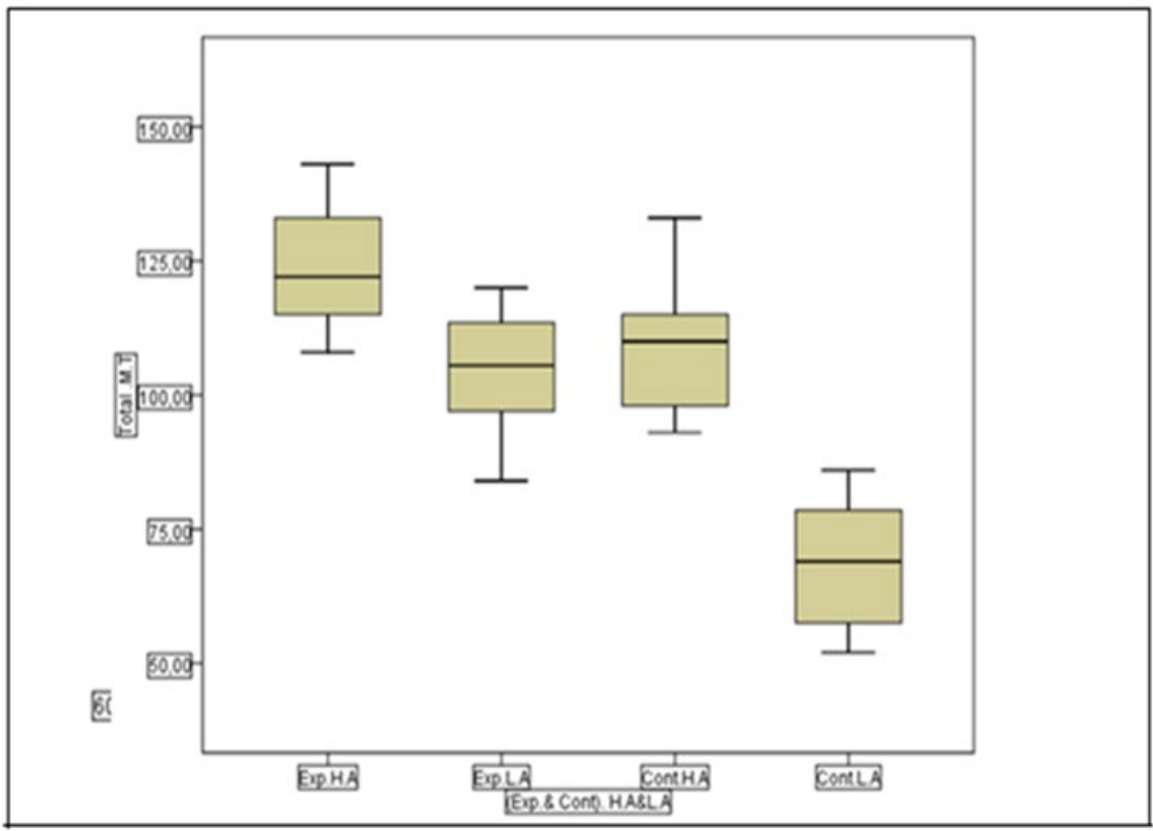

Figure 2. Box plot for the comparison of M.T scores across the group

\section{DISCUSSION}

The difference between the means' scores of the corresponding nested factors of the two groups that is (Exp. and Cont. high achievers groups) and (Exp. and Cont. low achievers groups) on the mathematical-thinking post-tests are insignificant". As a result, these two hypotheses were rejected. The differences in the means and standard deviations in (Table 2) were in the favor of the experimental group in comparison with the control group. Moreover, the p- values in the multiple comparison Table 4 for Exp.H.A and Cont.H.A is 0.031, likewise, for Exp.L.A and Cont.L.A, the p-value is nearly 0, as both the values are less than 0.05. These results explored that geogebra was equally in use of nested factors, and it equally improved the M.T of Exp. group at significance. As well, these results findings are parallel to the study of Gillani (2005), as she selected 80 students (grade-10) sample for her experimental study, out of which 52 were constituted for higher achiever and 28 students were included for lower achievers, she used instructional technology in the teaching of biology, and the finding assured that both of the experimental higher and lower achievers groups improved at significance as compared to the control high and low achievers. By the same token, it supports the study of Jena (2013) and Safdar (2013) too. In conclusion, Geogebra is the best scaffolding tool in developing grade-12 students' mathematical thinking in the subject of analytic geometry. Geogebra affected both the high and low achievers of experimental students' mathematical thinking at significance in comparison to control group.

\section{ACKNOWLEDGEMENTS}

The researcher express his deep sense of thanks and gratitude to the honorable body of Higher Education commission (HEC) Pakistan for its award of scholarship under the indigenous 5000 PhD fellowship program for the research study, and the International Research Support Initiative Program (IRSIP) for Middle East Technical University Ankara (METU Ankara), where the researcher refined and accomplished his research.

\section{Disclosure statement}

No potential conflict of interest was reported by the authors.

\section{Notes on contributors}

Muhammad Khalil - Lecturer, FG Boys Inter College Mardan Cantt., Pakistan.

Umair Khalil - Assistant Professor, AWKUM Mardan, Pakistan.

Zahoor ul Haq - Lecturer, Department of Education, Bacha Khan University Charsadda KPK, Pakistan. 


\section{REFERENCES}

Amirali, M., \& Halai, A. (2010). Teachers' knowledge about the nature of mathematics: A survey of secondary school teachers in Karachi, Pakistan. Bulletin of Education and Research, 32(2), 45-61. Retrieved from http://pu.edu.pk/images/journal/ier/PDF-FILES/3-Munira\%20Almirani.pdf

Ang, K. C. (2010). Teaching and learning mathematical modeling with technology. In Proceedings of the 15th Asian Technology Conference in Mathematics, Beijing, China, pp.19-29.

Ary, D., Jacobs, L. C., Sorensen, C., \& Walker, D. A. (2013). Introduction to research in education (9th Ed.) (pp. 328-329). California: Wadsworth.

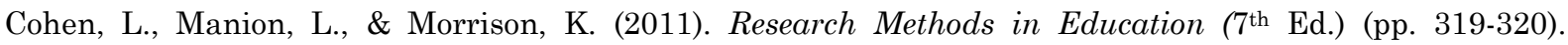
Routledge: USA.

Dindyal, J. (2007). The need for an inclusive framework for students' thinking in school geometry. The Montana Mathematics Enthusiast, 4(1), 73-83.

EMIS. (2013-2014). Annual Statistical Report of Government Schools, Elementary \& Secondary Education Department (pp. 2-11), Pakistan: Government of Khyber Pakhtunkhwa. Retrieved from http://www.kpese.gov.pk/ASCMain.html

Evans, B. R. (2014). The development of Mathematics throughout the centuries: A brief History in a cultural context, Chapter No.12, (pp. 123-127). Hoboken, New Jersey: John Wiley \& Sons, Inc.

Farooq, R. A. (2001). Understanding Research in Education (P-11, 29, 90). Rawalpindi; University of Arid Agriculture.

Gay, L. R., \& Mills, G. E. (2009).Educational Research: Competencies for Analysis and Application (9 ${ }^{\text {th }}$ Ed.) (pp. 222). Islamabad: National Book Foundation.

Gillani, S. N. (2005). Effectiveness of Instructional Technology in Teaching of Biology to Secondary School Students (PhD thesis), Rawalpindi, University Institute of Education and Research; University of Arid Agriculture.

Gómez-Chacón, I. M ${ }^{\mathrm{a}}$, \& Joglar, N. (2010). Developing competencies to teach exponential and logarithmic functions using GeoGebra from a holistic approach, Educação Matemática Pesquisa., São Paulo, 12(3), 485-513.

Goodwin, C.J. (2010). Research in Psychology: Methods and Design (6 ${ }^{\text {th }}$ Ed.) (pp. 176, 211-214). New York: John Wiley.

Gravetter, F. J., \& Wallnau, L. B. (2012). Statistics for the Behavioral Sciences (9 ${ }^{\text {th }}$ Ed.). Wadsworth Publishing (pp. 416). Retrieved from http://craftx.org/sites/all/themes/craft_blue/pdf/Exploring_College _Textbook_Sample_2_p3.pdf

Hergenhahn, B. R., \& Henley, T. B. (2013). An introduction to the history of Psychology (7th Ed.), Chapter No 4, p.111. USA: Wadsworth Cengage Learning.

Jena, P. C. (2013). Effect of Smart Classroom Learning Environment on Academic Achievement of Rural High Achievers and Low Achievers in Science. International Letters of Social and Humanistic Sciences, 3, 19.

KPK Textbook Board. (2006). Mathematics II: Calculus with Analytic Geometry (pp. 219). Peshawar: The KPK Text Board.

Kushwaha, R. C., Chaurasia, P. K., \& Singhal, A. (2013). Creating Dynamic Webpage for GeoGebra Quiz Applet; International Journal of Information and Computation Technology, 3(3), 175-180

Lew, H. (2004). Developing Algebraic Thinking in the Earlier Grades: A Case Study of the South Korean Elementary School Mathematics Curriculum. The Mathematics Educator, 8, 88-106.

Little, C. (2009). Differentiation in three easy, GeoGebra-style, lessons. MSOR Connections, 9(2), 27-30. https://doi.org/10.11120/msor.2009.09020027

Ljajko, E., \& Ibro, V. (2013). Development of ideas in a GeoGebra - aided mathematics instruction. Mevlana International Journal of Education, 3(3), 1-7. https://doi.org/10.13054/mije.si.2013.01

National Curriculum for Mathematics. (2006). Ministry of Education, Government of Pakistan. Retrieved from http://www.ibe.unesco.org/curricula/pakistan/pk_al_mt_2006_eng.pdf

NCTM. (2000). Executive Summary Principles and Standards for School. Retrieved from http://www.nctm.org/uploadedFiles/Standards_and_Positions/PSSM_ExecutiveSummary.pdf 
Khalil et al.

Nestor, P. G. \& Schutt, R. K. (2014). Research Methods in Psychology: Investigation Human Behavior (2 ${ }^{\text {nd }}$ Ed.), pp. 155-156.

Newby, P (2014). Research Methods for Education (2nd Ed) (pp.122-125). Pearson Education Ltd.

Özgün-Koca, S. A., \& Meagher, M. (2012). Birth of a Virtual Manipulative .North American GeoGebra Journal, 1(1), 27-32.

Safdar, A. (2013). Effectiveness of Information and Communication Technology (ICT) in Mathematics at Secondary Level (PhD Thesis), IIUI Pakistan.

Shimamoto, D. (2012). Implementing a Flipped Classroom: An Instructional Module. Retrieved from http://scholarspace.manoa.hawaii.edu/handle/10125/22527

http://www.iejme.com 